The use of port central venous catheters (CVCs) for chemotherapeutical use has seen exponential growth over the last decades. However, port CVC misplacement may lead to catheter malfunction (such as partial or total catheter blockade), which might be complicated by thrombosis and catheter superinfections, and these in turn may lead to pulmonary embolism and bloodstream infections. The overall occurrence of port CVC misplacement is up to $6 \%$; nonetheless, port CVC misplacement may occur in up to $67 \%$ of patients with early CVC dysfunction (occurring within three months of catheter insertion). Thereafter, the prompt evaluation of catheter position among patients with first-trimester CVC dysfunction is extremely important. The aim of the present manuscript is to support medical oncologists, haematologists, and clinicians in timely suspicion and recognition of port CVC misplacement among patients with early CVC dysfunction. Radiological educational iconographic materials that will assist a prompt estimate of port-CVC dislocation are provided.

Key words: central venous catheters, port, chemotherapy, CVCs, dysfunction, misplacement.

Contemp Oncol (Pozn) 2018; 22 (2): 129-134 DOI: https://doi.org/10.5114/wo.2018.77044

\section{Identification of catheter misplacement in early port CVC dysfunction}

\author{
Davide Mauri ${ }^{1,2}$, Georgia Zafeiri ${ }^{1}$, Lampriani Tsali ${ }^{3}$, Anastasia Chalkidou ${ }^{2}$, \\ Georgios Zarkavelis ${ }^{1}$, Alexandra Papadaki ${ }^{1}$, Panagiotis Filis ${ }^{1}$, \\ George Pentheroudakis ${ }^{1}$
}

${ }^{1}$ Department of Medical Oncology, University Hospital of Ioannina, Greece

${ }^{2}$ Department of Chemotherapy, General Hospital of Lamia, Greece

${ }^{3}$ Department of Internal Medicine, General Hospital of Lamia, Greece

\section{Introduction}

A portacath is a subcutaneously implanted central venous access device that provides an "any-time" venous access for patients with inadequate peripheral veins. Port central venous catheters (CVCs) are also implanted among patients who are in need of outpatient-based continuous administration of chemotherapy, total parenteral nutrition, or antibiotics; and in in-patient settings among patients who are in need of frequent administration of chemotherapy and blood sampling, as well as in patients with chemotherapy-induced recurrent thrombophlebitis. For these reasons the use of port central venous catheters (CVCs) has had an exponential growth over the last decades in both haematology and oncology settings. Guidelines on central venous access in oncology have been provided both by ESMO and ASCO [1, 2].

Outpatient infusion therapy with permanent indwelling port CVCs may sometimes be complicated by catheter malfunction (such as partial or total blockade), bloodstream infections, thrombosis, and pulmonary embolism [1-5].

Port CVC misplacement is an important cause of catheter malfunction and thrombosis $[5,6]$. An accurate port CVC placement may indeed represent the most effective tool in minimising CVC-associated thrombotic complications [5].

Despite the fact that port-CVC misplacement is an uncommon event and its occurrence is estimated to be up to $6 \%[3,7]$, a prospective study from Harvard Brigham and Women's Hospital underscored that the occurrence of port CVC malposition might be up to $67 \%$ in patients with early CVC dysfunction (dysfunction occurring within three months of CVC insertions) [7].

In direct contrast with the increasing use of port CVCs and the potential harm related to CVC misplacement sequels, no educational iconographic material is currently available to assist clinicians in prompt recognition of port CVC misplacement. This in turn may result in diagnostic delay, lead to avoidable sequels, and jeopardise the patients' safety.

Nevertheless, the delay might be further worsened in cases where physicians implanting port CVCs operate in medical centres different from the chemotherapy unit where the drugs are delivered to the patients, and oncologists/haematologists might not be experienced in evaluating port-CVC misplacement. In the Bansal study $20 \%$ of malfunctioning CVCs were inserted in different institutions than the one where the chemotherapies were delivered [6].

Thus, the aim of the present educational manuscript is to support medical oncologists, haematologists, and clinicians in prompt suspicion, recognition, and management of port-a-cath catheter misplacement among patients with early port CVC malfunction. 


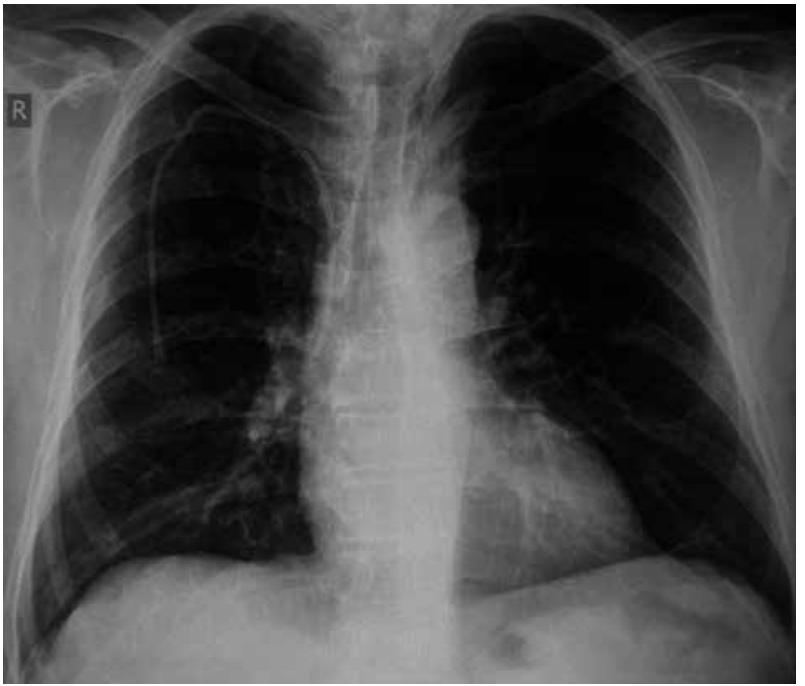

Fig. 1. Correct placement. Catheter tip terminates in the superior vena cava, just upstream of the right atrium

\section{Where should the catheter be placed?}

The insertion of an implantable port-CVC devices is generally percutaneous, either using the internal jugular vein under 2D ultrasound guidance or subclavian vein access [1]. Ideally, the catheter tip should terminate in the superior vena cava, just upstream of the right atrium (Figs. 1, 2).

The catheter tip position should be verified radiologically with an intraoperative fluoroscopy or a postoperative chest $\mathrm{X}$-ray. The evaluation with postplacement radiograph results in a 50\% decrease in the incidence of suboptimal positioning [6].

Early catheter malfunction is any catheter dysfunction occurring within three months of a port-CVC insertion.

Dysfunction is generally due to partial blockade (inability to flush or withdraw fluids from the port, reduced flow rate) or complete blockade (no catheter flow in any direction).

\section{First signs and symptoms of misplacement}

Generally, the first sign of catheter malfunction is difficulty in aspirating or infusing/flushing through the lumen of the catheter. The patient may complain of pain or a burning sensation during injection. In case of misplacement with the catheter tip in the internal jugular vein (leading to inverted flow with turbulence), an acute pain or disturbance in the ipsilateral ear may be reported during flushing. A loop of the catheter in the jugular vein is generally associated with a sensation of pressure, tenderness, and local pain; the presence of the catheter loop is frequently palpable through the skin during clinical examination. Arrhythmias might also occur in cases of right atrial and particularly in right ventricular positioning of the catheter tip.

\section{How to investigate it}

Firstly, it is useful to rule out minor causes of total or partial port-CVC blockade dysfunction.

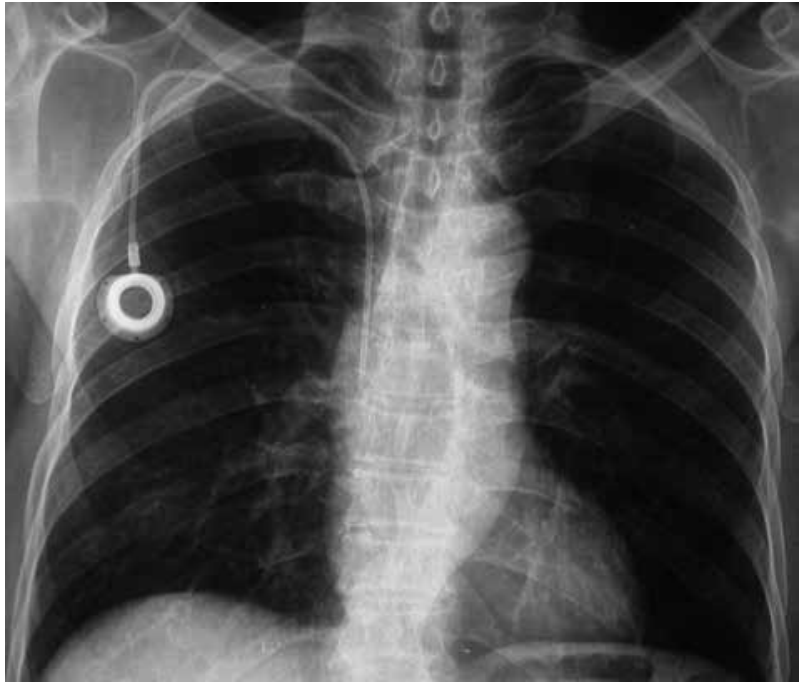

Fig. 2. Correct placement. Catheter tip terminates in the superior vena cava, just upstream of the right atrium

- If the catheter tip blocked by catheter decubitus on the superior vena cava vessel wall, changing the patient's posture may lead to catheter functioning.

- Postural changes of the patient may be of value even in bypassing the pinch-off syndrome (in the case of subclavian access, the catheter is compressed during its passage through the narrow angle between the first rib and the lateral position of the clavicle) and lead to catheter patency.

- Performing a single cycle of fibrinolytic therapy (intracatheter dwell with alteplase $1 \mathrm{mg} / \mathrm{ml}$ or urokinase $5000 \mathrm{lU} / \mathrm{ml}$ for 40 minutes) might be useful in unblocking central lines [8]. In the case of simple fibrin sheet or ball-valve-type clot on the tip of the catheter lumen the catheter patency will probably be restored.

Secondly, in case of malfunctioning port-catheters that do not respond to postural changes and to a single cycle of lytic therapy, catheter misplacement and thrombosis should be ruled out.

- A chest X-ray (face and profile) should be promptly obtained to evaluate possible catheter misplacement.

- A US Doppler evaluation of major venous vessels is mandatory to exclude catheter-related thrombosis.

It should be highlighted that instilling anything into a catheter that does not give a blood return, and use of pressure to overcome catheter blockade is against recommendations. Pushing fluid into a clotted catheter can dislodge a clot, causing it to travel into the lungs putting the patient at risk of pulmonary embolism.

\section{Radiological features for port CVC misplacement}

Catheter misplacement is the presence of the catheter in any position other than correct. This can be due to catheter mispositioning (catheter inserted in any position other than correct), catheter migration (catheters correctly placed but successively migrated to an incorrect position), or catheter fracture (catheter breakage). To ease the prompt recognition of port CVC misplacement among 


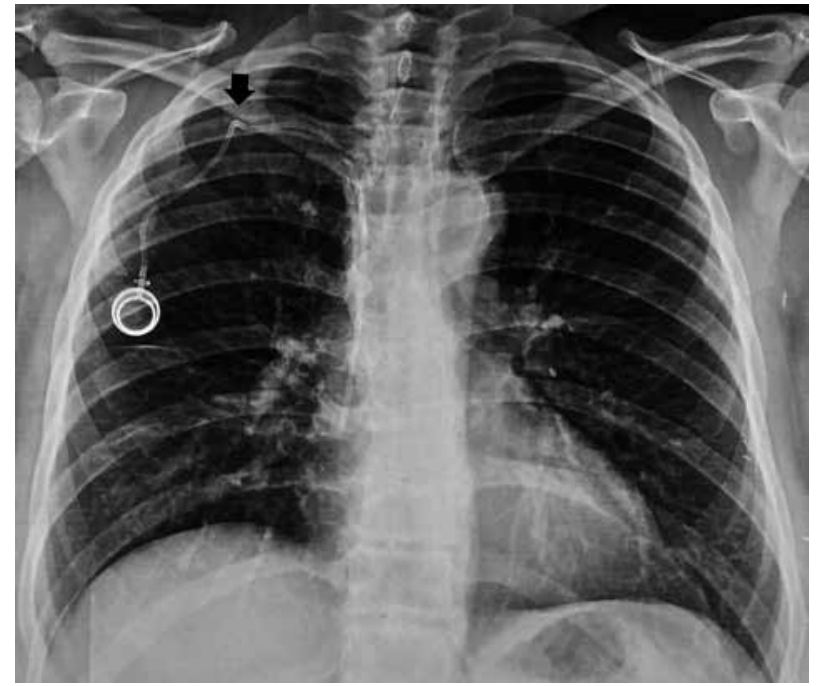

Fig. 3. Catheter kinked due to compression between the first rib and the clavicle, thus resulting in pinch-off syndrome

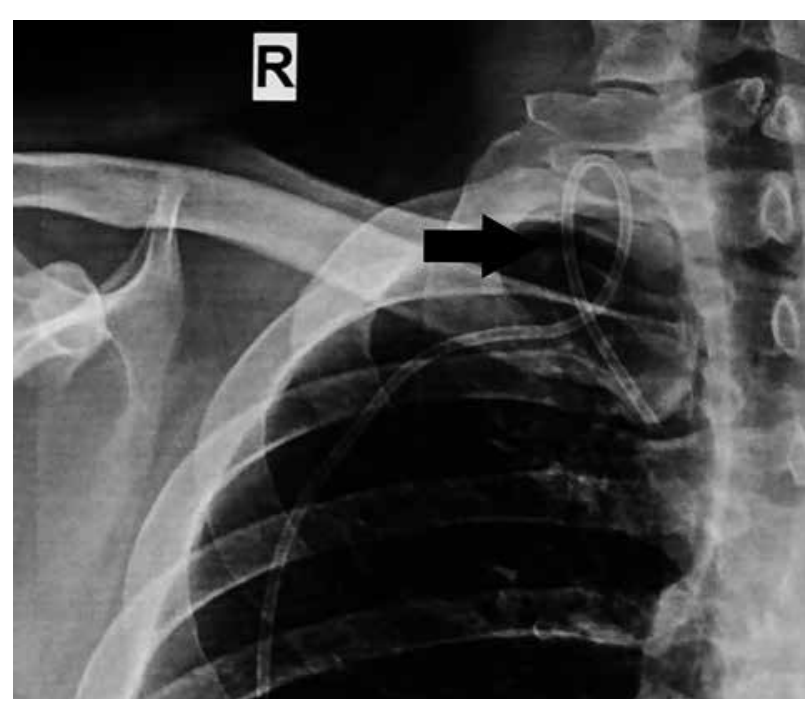

Fig. 5. Catheter makes a loop in the ipsilateral jugular vein

patients with early CVC dysfunction, we provide a photographic review of radiologic pathological features. The aim is to speed up diagnosis and to help clinicians to become familiar with different pathological radiological conditions.

Common radiological features of CVC catheter misplacement are provided below.

- Catheter compressed during its passage through the narrow angle between the first rib and the lateral position of the clavicle, resulting in pinch-off syndrome (Fig. 3).

- Catheter mispositioning in the inferior vena cava (Fig. 4). These patients generally report an extremely laborious and difficult positioning of the catheter with associated palpitation, tachycardia, arrhythmias, and sensation of sudden death during the catheter insertion procedure.

- Catheter loop in the venous lumen (Figs. 5, 6). Loop in vein lumen results in flow turbulence and thrombosis.

- Catheter migration in the contralateral subclavian vein (Fig. 7).

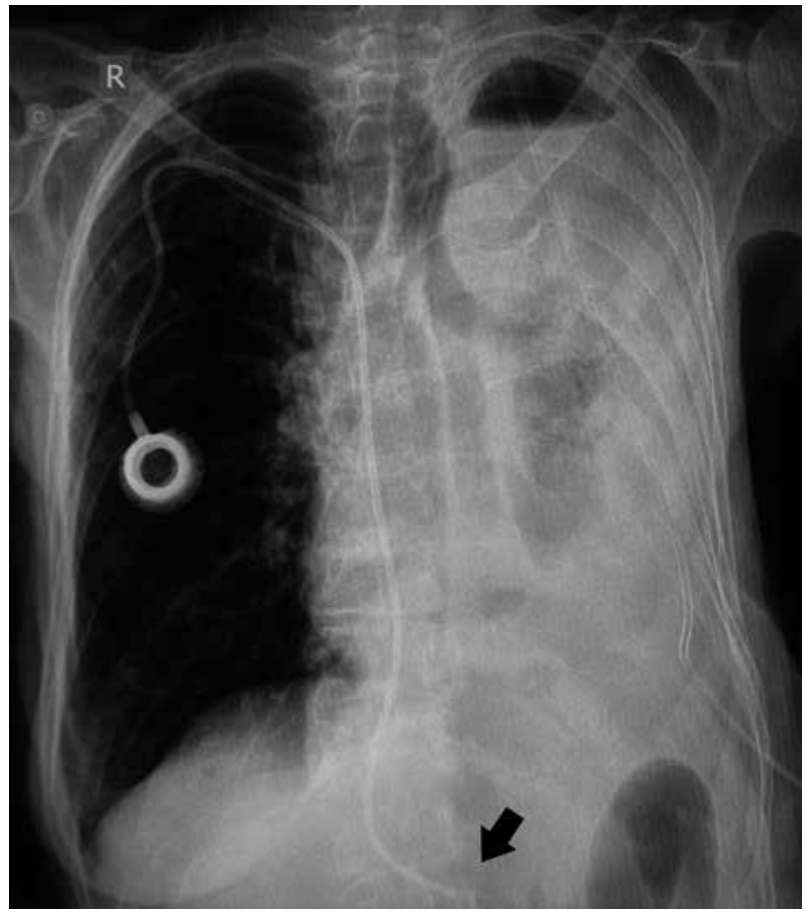

Fig. 4. Long catheter with catheter tip reaching the inferior vena cava

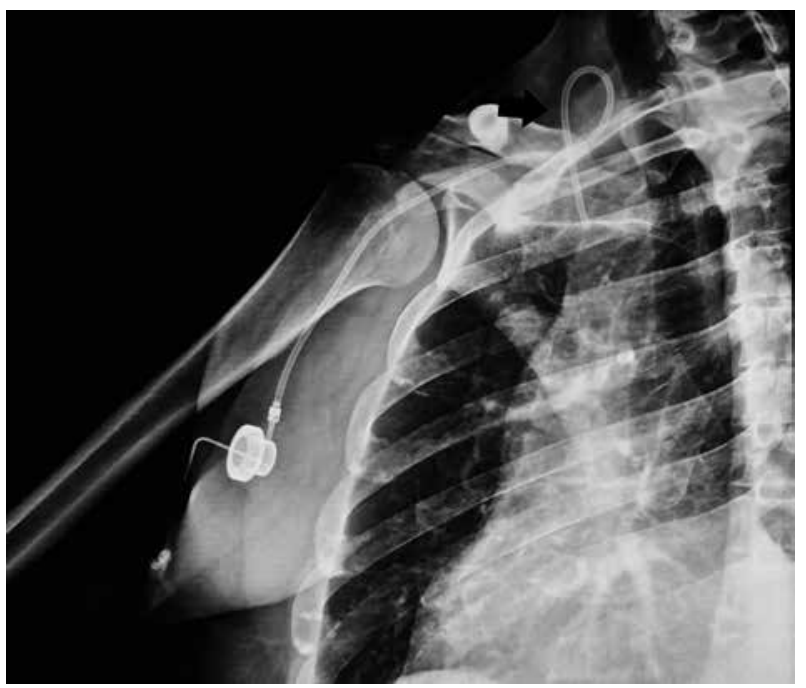

Fig. 6. Catheter makes a loop in the ipsilateral jugular vein

- Catheter tip in the ipsilateral jugular vein (Fig. 8).

- Tight suture (Figs. 9, 10).

- Catheter length with endocardial loop in the right atrium (Fig. 11). Palpitation, tachycardia, arrhythmias may occur during the catheter insertion procedure.

- Catheter fracture (Figs. 12, 13).

- Catheter shortness (Figs. 14, 15).

- Narrow angle loop before entering the subclavian vein (Figs. 16, 17).

- Catheter kinking: a catheter tight curl, twist, or bend from any cause and at any site of the catheter, causing its malfunction. In the reported figures kinks are due to pinch-off syndrome, tight sutures, or narrow angle loops (Figs. 3, 9, 10, 16, 17). 


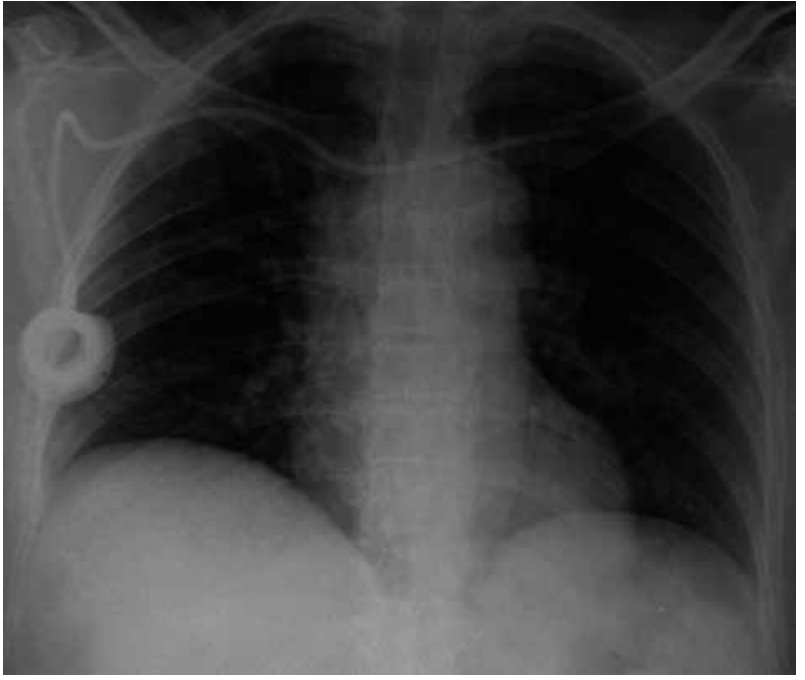

Fig. 7. Catheter is too long and ends in the contralateral subclavian vein

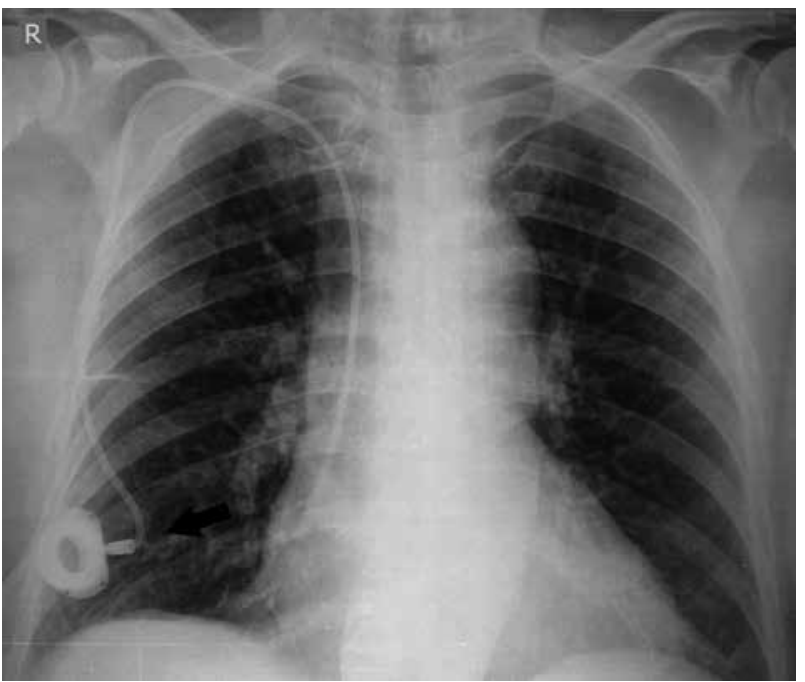

Fig. 9. Tight suture generating a catheter kinking right after the port. As a result, there is a mechanical obstruction that blocks flow in any direction

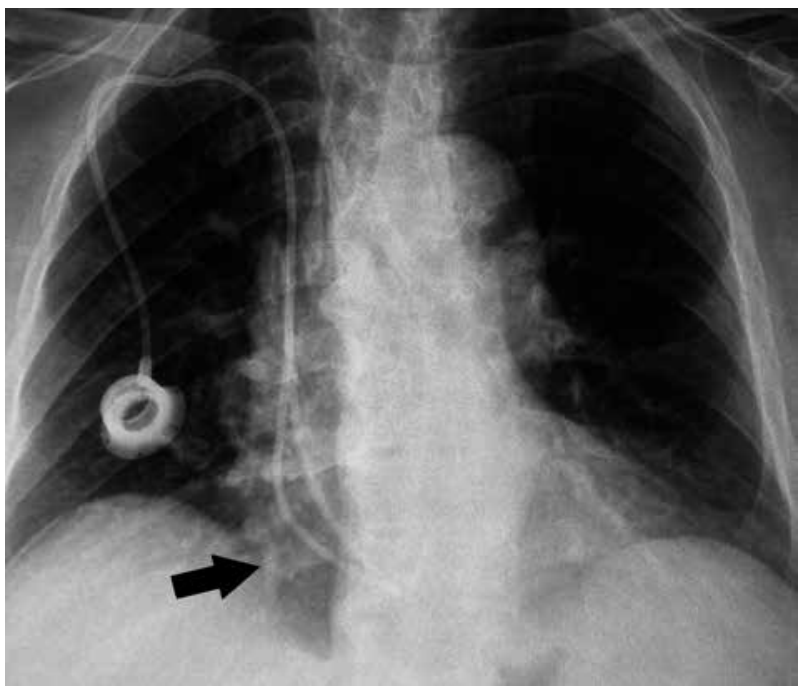

Fig. 11. Chest $\mathrm{X}$-ray indicates a long catheter with endocardial loop in the right atrium

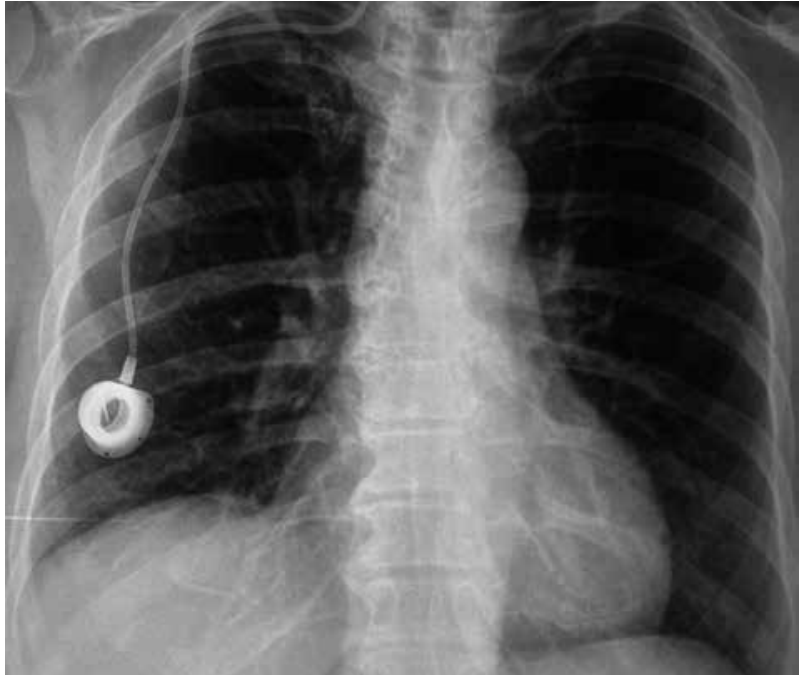

Fig. 8. Catheter has entered the right subclavian vein and then continues to the right internal jugular vein

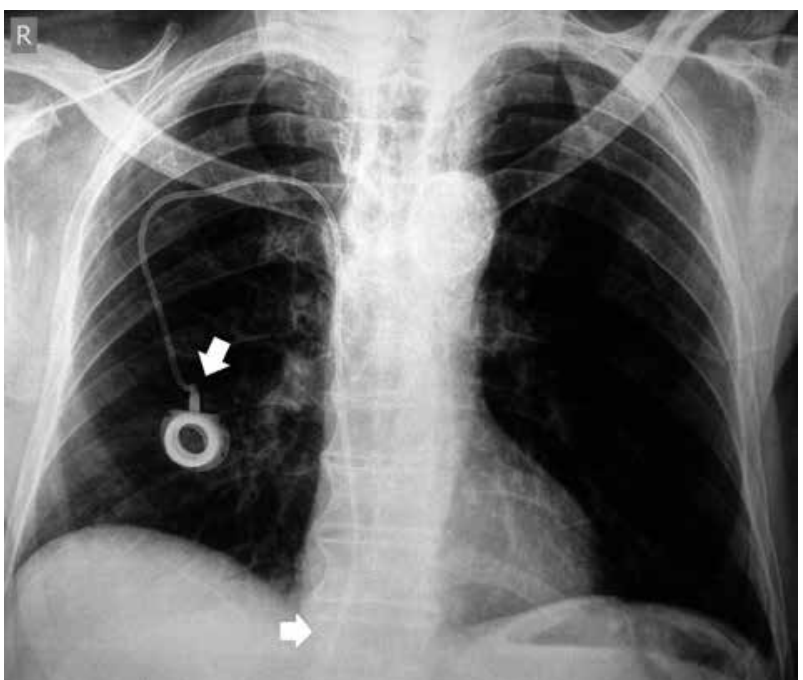

Fig. 10. Tight suture generating a catheter kink right after the port We can also see catheter length with catheter tip misplaced and reaching the inferior vena cava

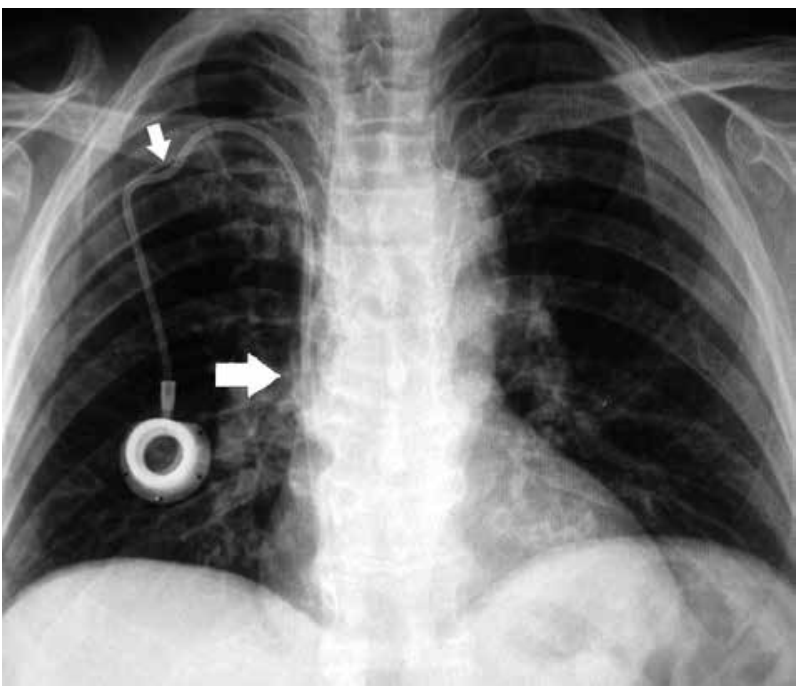

Fig. 12. The chest $X$-ray shows a catheter fracture in the right atrium. The fragment must be removed immediately to avoid life-threatening complications. We can also see a pinch-off syndrome due to catheter compression between the first rib and the clavicle 


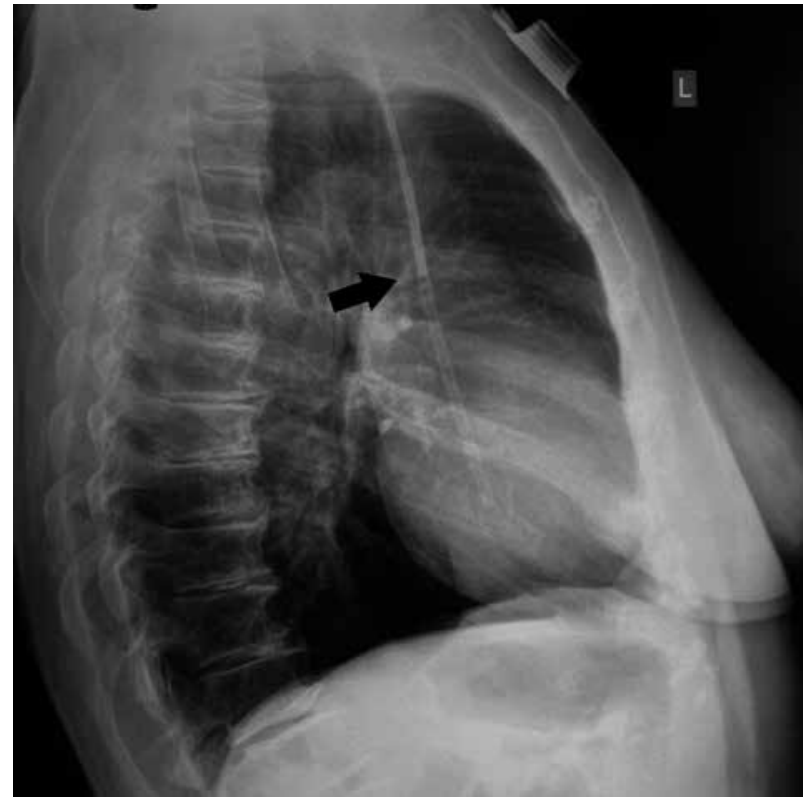

Fig. 13. The chest X-ray (profile view) shows a catheter fracture in the right atrium

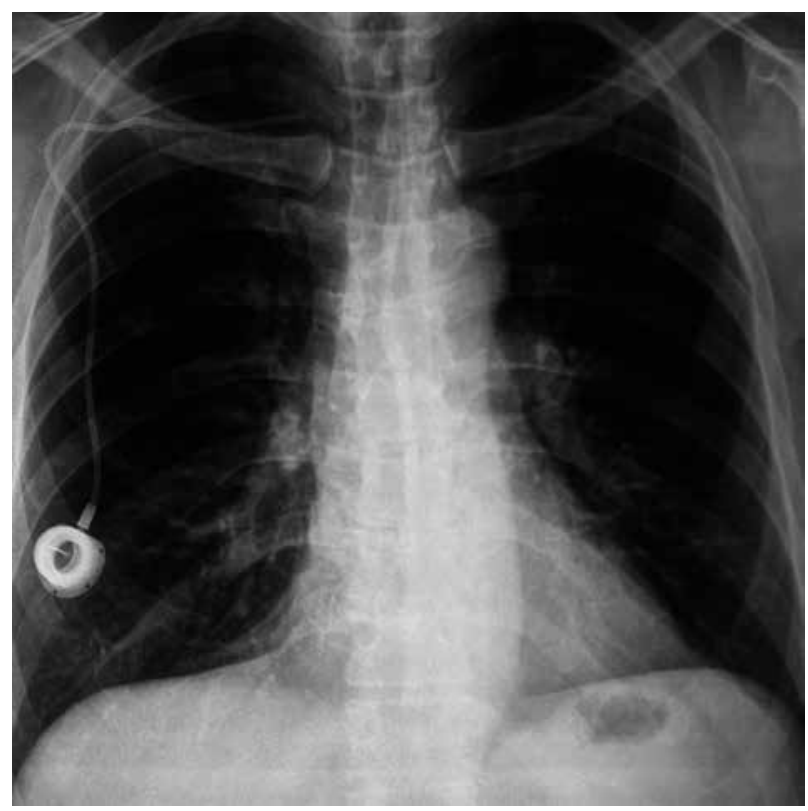

Fig. 15. Short catheter: due to its shortness the catheter has migrated outside the superior vena cava

If any port CVC misplacement is recognised (mispositioning, migration fracture, kinking, etc.), the patient should immediately be forwarded to an interventional radiology department for correction, repositioning, or removal. A list of possible corrections is listed in the flow chart (Fig. 18).

In case of co-presence of thrombosis, a short course (3-5 days) of anticoagulation therapy is recommended before managing or removing the catheter, in order to avoid clot embolism [1].

Of note, many port CVCs are accidentally inserted with the catheter tip in the right atrium. In this case, if the cath-

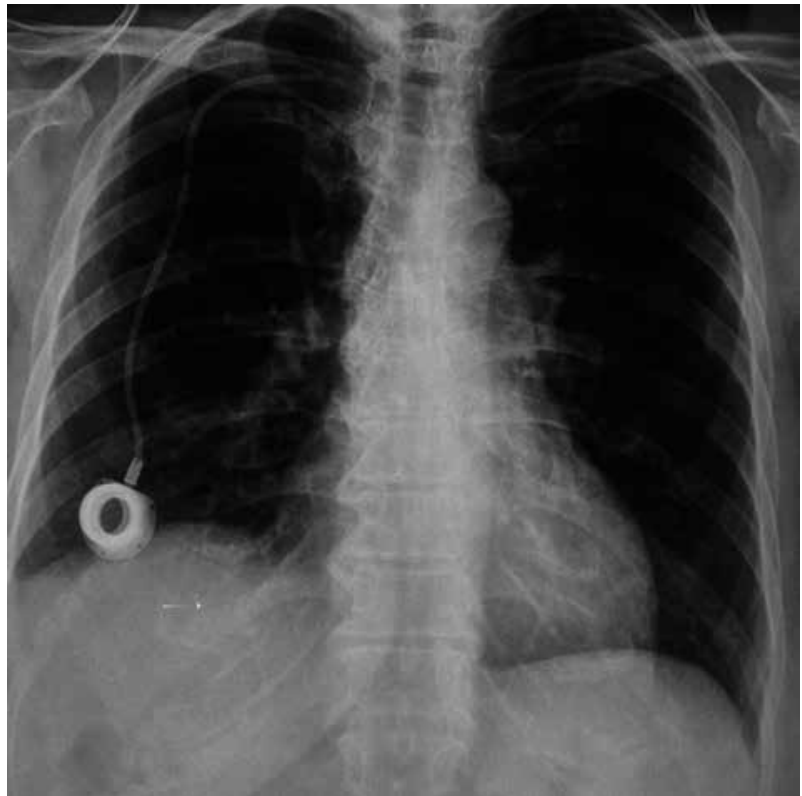

Fig. 14. Short catheter with catheter tip just at the entrance of the right subclavian vein. There is an extremely high risk of drug extravasation with minimal catheter back movement/migration

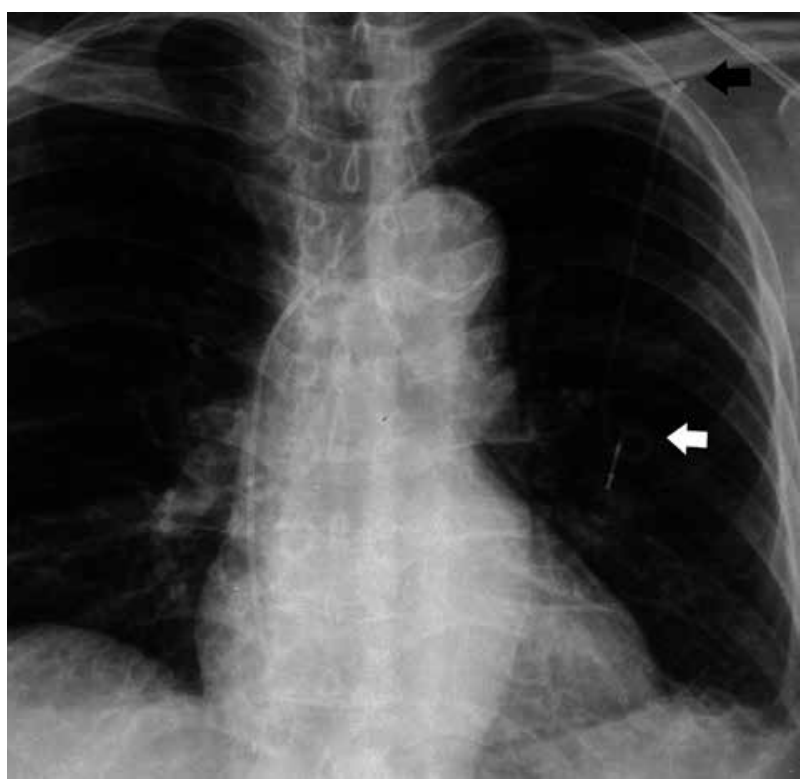

Fig. 16. Catheter length with a narrow angle loop immediately after the port and a second narrow angle distortion before its entrance in the subclavian vein

eter is functioning and it is not complicated by blockage, thrombosis, infections, or arrhythmias, the device can be maintained and used without repositioning or removal.

\section{Conclusions}

Early malfunction of port CVCs is strongly associated with port catheter misplacement. Considering the potential harm related to CVC misplacement sequels, patients with malfunction of their indwelling port CVCs, who do not respond to a single cycle of fibrinolytic therapy, should undergo prompt radiological evaluation of catheter position and U/S 2D Doppler evaluation of major vessels. 


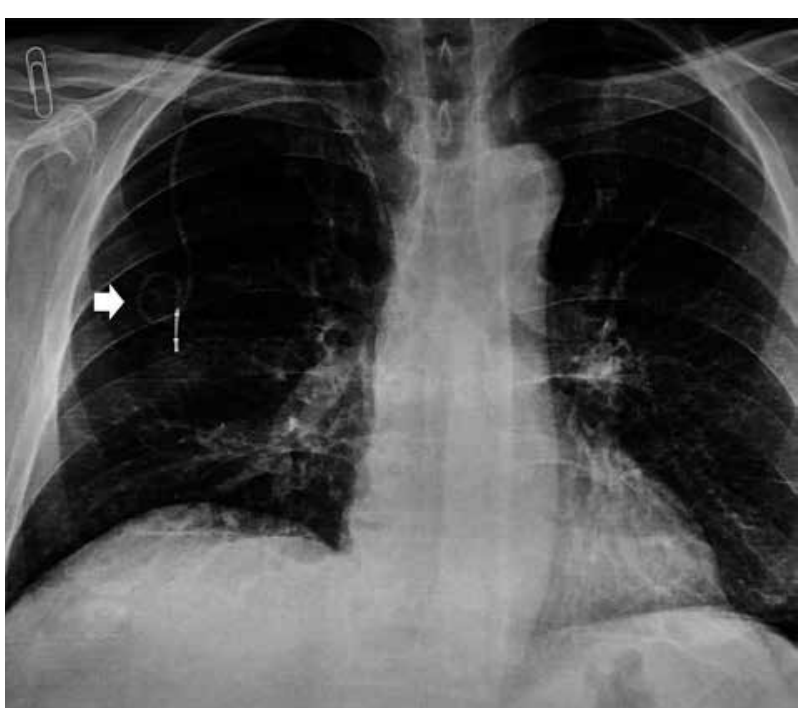

Fig. 17. Catheter length with a narrow angle loop immediately after the port

The authors declare no conflict of interest.

\section{References}

1. Sousa B, Furlanetto J, Hutka M, Gouveia P, Wuerstlein R, Mariz JM, Pinto D, Cardoso F; ESMO Guidelines Committee. Central venous accesss in Oncology: ESMO Clinical Practice Guidelines. Ann Oncol 2015; 26 (Suppl. 5): 152-168.

2. Schiffer CA, Mangou PB, Wade JC et al. Central Venous Catheter care for the patient with cancer: American Society of Clinical Oncology Clinical Practice Guideline. J Clin Oncol 2013; 17: 1357 1370.

3. Granic M, Zdravkovic D, Krstajic S, et al. Totally implantable central venous catheters of the port-a-cath type: complications due to its use in the treatment of cancer patients. J BUON 2014; 19: 842-846.

4. Mauri D, Roumbkou S, Michalopoulou S, Tsali L, et al. Port central venous catheters associated bloodstream infection during outpatient-based chemotherapy. Med Oncol 2010; 27: 1309-1313.

5. Wiegering V, Schmid S, Andres O, et al. Thrombosis as a complication of central venous access in pediatric patients with malignancies: a 5-year single-center experience. BMC Hematol 2014; 14: 18.

6. Bansal A, Binkert C, Robinson MK, Shulman LN, Pellerin L, Davison B. Impact of quality management monitoring and intervention on central venous catheter dysfunction in the outpatient chemotherapy infusion setting. J Vasc Interv Radiol 2008; 19: 1171-1175.

7. Kim HJ, Yun J, Kim HJ, et al. Safety and effectiveness of central venous catheterization in patients with cancer: prospective observational study. J Korean Med Sci 2010; 25: 1748-1753.

8. Pollo V, Dionízio D, Bucuvic EM, Castro JH, Ponce D. Alteplase vs. urokinase for occluded hemodialysis catheter: A randomized trial. Hemodial Int 2016; 20: 378-384.

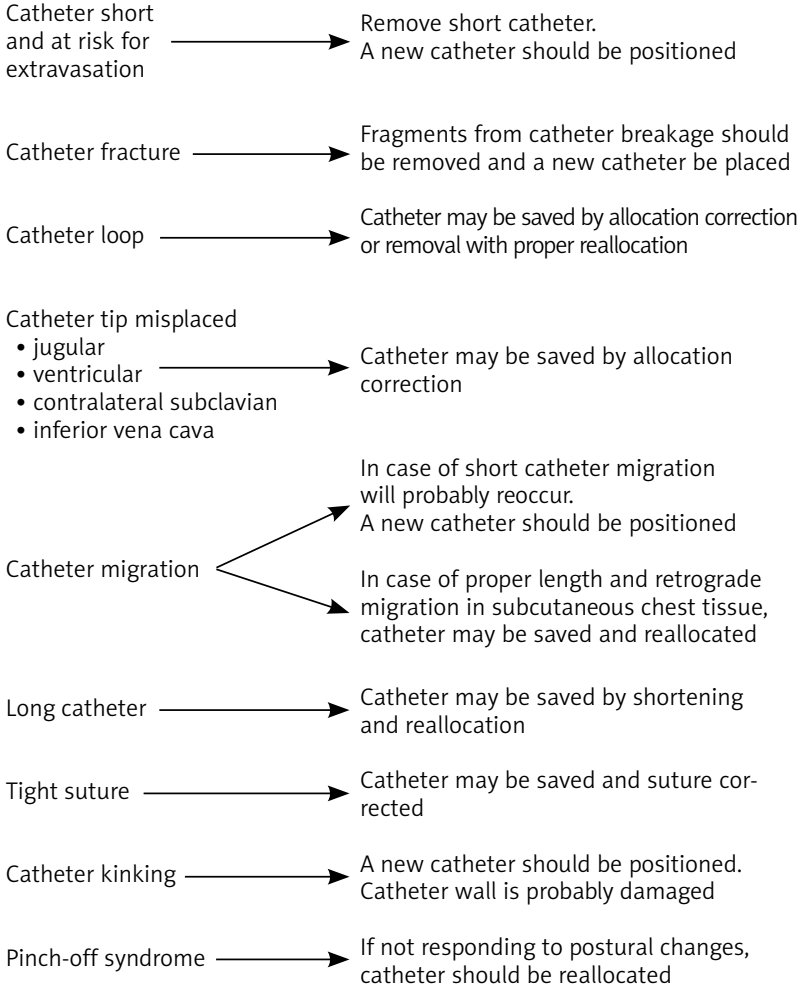

Fig. 18. Flow chart with suggestions on how to manage port-catheter misplacement

\section{Address for correspondence \\ Davide Mauri \\ University Hospital of Ioannina \\ Leof. Stavrou Niarchou \\ 45500 loannina, Greece \\ e-mail: dvd.mauri@gmail.com}

Submitted: 22.01 .2018

Accepted: 24.03 .2018 